\title{
Dexamethasone Treatment Reverses Cognitive Impairment but Increases Brain Oxidative Stress in Rats Submitted to Pneumococcal Meningitis
}

\author{
Tatiana Barichello, ${ }^{1}$ Ana Lucia B. Santos, ${ }^{1}$ Cintia Silvestre, ${ }^{1}$ \\ Jaqueline S. Generoso, ${ }^{1}$ Andreza L. Cipriano, ${ }^{1}$ Fabricia Petronilho, ${ }^{2}$ \\ Felipe Dal-Pizzol, ${ }^{2}$ Clarissa M. Comim, ${ }^{3}$ and João Quevedo ${ }^{3}$ \\ ${ }^{1}$ Laboratory of Experimental Microbiology and National Institute for Translational Medicine (INCT-TM), Postgraduate Program in \\ Health Sciences, Health Sciences Unit, University of Southern Santa Catarina, 88806-000 Criciuma, SC, Brazil \\ ${ }^{2}$ Laboratory of Pathophysiology and National Institute for Translational Medicine (INCT-TM), Postgraduate Program in Health \\ Sciences, Health Sciences Unit, University of Southern Santa Catarina, 88806-000 Criciúma, SC, Brazil \\ ${ }^{3}$ Laboratory of Neurosciences and National Institute for Translational Medicine (INCT-TM), Postgraduate Program in Health Sciences, \\ Health Sciences Unit, University of Southern Santa Catarina, 88806-000 Criciuma, SC, Brazil \\ Correspondence should be addressed to Tatiana Barichello, tba@unesc.net
}

Received 7 February 2011; Revised 26 August 2011; Accepted 7 September 2011

Academic Editor: Ersin Fadillioglu

Copyright (๑) 2011 Tatiana Barichello et al. This is an open access article distributed under the Creative Commons Attribution License, which permits unrestricted use, distribution, and reproduction in any medium, provided the original work is properly cited.

Pneumococcal meningitis is associated with a significant mortality rate and neurologic sequelae. The animals received either $10 \mu \mathrm{L}$ of saline or a $S$. pneumoniae suspension and were randomized into different groups: sham: placebo with dexamethasone $0.7 \mathrm{mg} / \mathrm{kg} / 1$ day; placebo with dexamethasone $0.2 \mathrm{mg} / \mathrm{kg} / 7$ days; meningitis groups: dexamethasone $0.7 \mathrm{mg} / \mathrm{kg} / 1 \mathrm{day}$ and dexamethasone $0.2 \mathrm{mg} / \mathrm{kg} / 7$ days. Ten days after induction we evaluated memory and oxidative stress parameters in hippocampus and cortex. In the step-down inhibitory avoidance task, we observed memory impairment in the meningitis group with dexamethasone $0.2 \mathrm{mg} / \mathrm{kg} / 7$ days. The lipid peroxidation was increased in hippocampus in the meningitis groups with dexamethasone and in cortex only in the meningitis group with dexamethasone $0.2 \mathrm{mg} / \mathrm{kg} / 7$ days. The protein carbonyl was increased in hippocampus in the meningitis groups with dexamethasone and in cortex in the meningitis groups with and without dexamethasone. There was a decrease in the proteins integrity in hippocampus in all groups receiving treatment with dexamethasone and in cortex in all groups with dexamethasone $(0.7 \mathrm{mg} / \mathrm{kg} / 1$ day). The mitochondrial superoxide was increased in the hippocampus and cortex in the meningitis group with dexamethasone $0.2 \mathrm{mg} / \mathrm{kg} / 7$ days. Our findings demonstrate that dexamethasone reverted cognitive impairment but increased brain oxidative stress in hippocampus and cortex in Wistar rats ten days after pneumococcal meningitis induction.

\section{Introduction}

Streptococcus pneumoniae causes the worst acute bacterial infection of the central nervous system (CNS) [1]. Pneumococcal meningitis in adults results in cognitive speed loss [2], intracranial complications, brain edema, hydrocephalus, hippocampal apoptosis, and cortical necrosis [3]. Cognitive impairments were found in one-third of patients, and for this reason, large numbers of patients will continue to have complaints attributable to their illness after the acute phase of the disease [4]. The inflammatory host response in the subarachnoid space seems to be associated with unfavorable outcomes, accompanied by intrathecal production of multiple mediators, including the TNF- $\alpha$, IL- $1 \beta$ IL-6 [5], and matrix metalloproteinases; in consequence, polymorphonuclear leukocytes are attracted and activated. As a result, large amounts of nitric oxide and reactive oxygen species (ROS) are produced [6]. The brain is particularly vulnerable to ROS, brain cells' membranes are rich in polyunsaturated fatty acids that can be oxidized [7] leading to lipid peroxidation, 
DNA modification, and cellular dysfunction [8]. Furthermore, treatments with antioxidants have demonstrated to prevent the brain damage [9], attenuating meningeal inflammation, blood-brain barrier breakdown, and intracranial hypertension [10]. Dexamethasone is a glucocorticoid, very well known to reduce inflammatory cascades, and is used in variety of clinical conditions where their immunosuppressive properties are beneficial [4]. However, the use of dexamethasone in bacterial meningitis is controversial [11]. In experimental animal model with pneumococcal meningitis, dexamethasone inhibited the matrix metalloproteinase expression [12], decreased neurological sequelae, and inhibited caspase-3 activity in adult rat model by Group B Streptococcus $[13,14]$. On the other hand, dexamethasone as an adjuvant therapy aggravated hippocampal apoptosis, reduced learning capacity [15], and did not prevent sensorineural hearing loss in pneumococcal meningitis in infant rats [16]. Thereby, in this study, we investigated the adjuvant therapy with dexamethasone in cognitive performance and oxidative stress in rats induced by pneumococcal meningitis.

\section{Material and Methods}

Male Wistar rats (3-4 months, 220-310 g) were obtained from our breeding colony (UNESC). The animals were housed five in a cage with food and water available ad libitum and maintained on a $12 \mathrm{~h}$ light/dark cycle (lights on at 7:00 a.m.). All experimental procedures involving animals were performed in accordance with the NIH Guide for the Care and Use of Laboratory Animals and the Brazilian Society for Neuroscience and Behavior (SBNeC) recommendations for animal care and approved by the Animal Care and Experimentation Committee of UNESC, Brazil by protocol 84/2009.

2.1. Meningitis Model. All surgical procedures and bacteria administrations were performed under anesthesia consisting of an intraperitoneal (i.p.) administration of ketamine $(6.6 \mathrm{mg} / \mathrm{kg})$, xylazine $(0.3 \mathrm{mg} / \mathrm{kg})$, and acepromazine $(0.16 \mathrm{mg} / \mathrm{kg})$ [17]. S. pneumoniae was cultured overnight in $10 \mathrm{~mL}$ Todd Hewitt broth medium and grown for another $6 \mathrm{~h}\left(35^{\circ} \mathrm{C}, \mathrm{CO}_{2} 5.5 \%\right)$ and grown to logarithmic phase. The culture was centrifuged for $10 \mathrm{~min}$ at $5,000 \times \mathrm{g}$ and resuspended in sterile saline to the desired concentration and used for intracisternal injection [18, 19] containing $5 \times 10^{9} \mathrm{cfu} / \mathrm{mL}[14,20]$. On day 1 , the rats underwent a basilar cistern tap with a 23 -gauge needle. The position of the needle was verified by the free flow of clear cerebrospinal fluid. Cerebrospinal fluid was withdrawn and the animals received either $10 \mu \mathrm{L}$ of sterile saline $0.85 \%$ as a control (sham) or an equivalent volume of the $S$. pneumoniae. Cerebrospinal fluid (CSF) was obtained by intracisternal puncture at $16 \mathrm{~h}$ after infection, and $5 \mathrm{~mL}$ were cultured in serial dilutions on blood-agar plates to assess bacterial load $[18,21]$, followed by the initiation of the antibiotic treatment (ceftriaxone $100 \mathrm{mg} / \mathrm{Kg}$ twice a day, i.p., for seven days) [20]. The animals were randomized into different groups: sham: placebo group with dexamethasone $(0.7 \mathrm{mg} / \mathrm{kg} / 1$ day $)$ and placebo group with dexamethasone $(0.2 \mathrm{mg} / \mathrm{kg} / 7$ days $)$ and meningitis group with dexamethasone $(0.7 \mathrm{mg} / \mathrm{kg} / 1$ day) and meningitis group with dexamethasone $(0.2 \mathrm{mg} / \mathrm{kg} / 7$ days) [22]. Ten days after the induction of meningitis behavioral test was performed. After the behavioral test, the animals were sacrificed, and hippocampus and cortex were isolated to the determination of thiobarbituric acid reactive substances, protein carbonyls groups, sulphydryl groups, and mitochondrial superoxide.

\subsection{Behavioral Tests}

2.2.1. Step-Down Inhibitory Avoidance Task. This task evaluates aversive memory. The apparatus and procedures have been described in previous reports [23]. Briefly, the training apparatus was a $50 \times 25 \times 25 \mathrm{~cm}$ acrylic box (Albarsch, Porto Alegre, Brazil) whose floor consisted of parallel caliber stainless steel bars $(1 \mathrm{~mm}$ diameter) spaced $1 \mathrm{~cm}$ apart. A $7 \mathrm{~cm}$-wide, $2.5 \mathrm{~cm}$-high platform was placed on the floor of the box against the left wall. In the training trial, animals were placed on the platform, and their latency to step down on the grid with all four paws was measured with an automatic device. Immediately after stepping down on the grid, the animals received a $0.4 \mathrm{~mA}, 2.0 \mathrm{~s}$ foot shock and returned to their home cage. A retention test trial was performed $24 \mathrm{~h}$ after training (long-term memory). The retention test trial was procedurally identical to training, except that no foot shock was presented. The retention test step-down latency (maximum $180 \mathrm{~s}$ ) was used as a measure of inhibitory avoidance retention.

\subsection{Biochemical Assays}

2.3.1. Lipid Peroxidation. Lipid peroxidation was measured by formation of thiobarbituric acid (TBA) reactive substances (TBARS) after the method of Esterbauer and Cheeseman [24]. After brain dissection, brain structures were washed with PBS, harvested, and lysed. TBA $0.67 \%$ was added to each tube and vortexed. The optical density of each solution was measured in a spectrophotometer at $535 \mathrm{~nm}$. Data were expressed as nmoL of TBARS equivalents per $\mathrm{mg}$ of protein.

2.3.2. Protein Carbonyl Formation. Protein carbonyl content was measured in brain homogenates using 2,4dinitrophenylhydrazine (DNPH) in a spectrophotometric assay [25]. Absorbance was recorded in a spectrophotometer at $370 \mathrm{~nm}$ for both DNPH-treated and HCl-treated samples. Protein carbonyl levels were expressed as nmol of carbonyl per mg of protein. All the results were normalized by protein concentration measured by the Lowry assay [26].

2.3.3. Sulphydryl Groups. Total thiol content (Sulphydryl groups $-\mathrm{SH})$ in the brain was determined using the 5,5dithiobis(2-nitrobenzoic acid) (2-nitrobenzoic acid) method (DTNB). The conditions of DTNB measurement were as described previously [27], with some modifications. The absorbance at $412 \mathrm{~nm}$ was measured and amounts of TNB 


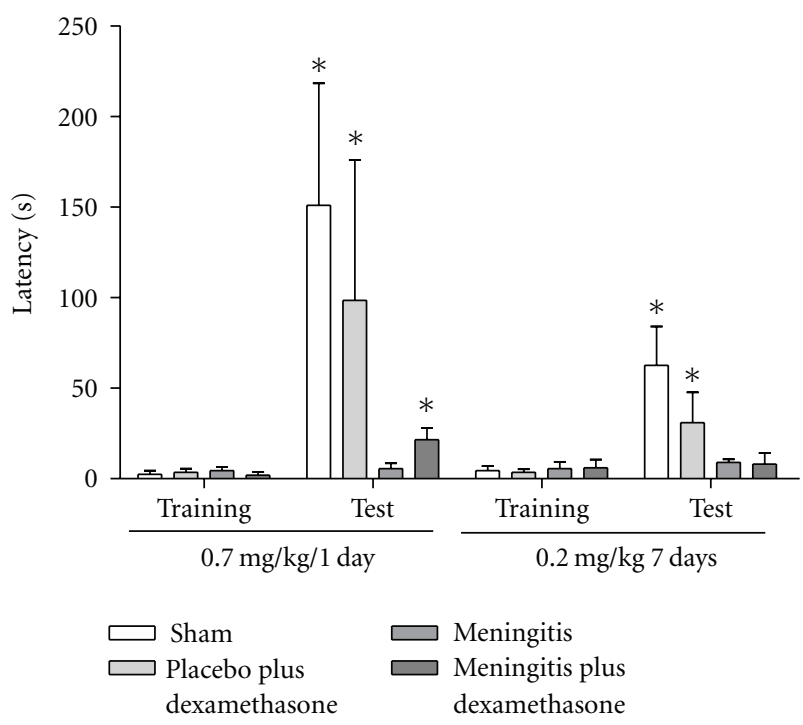

Figure 1: The step-down inhibitory avoidance. The step-down inhibitory avoidance test showed meningitis group with dexamethasone treatment $(0.7 \mathrm{mg} / \mathrm{kg} / 1$ day $)$ and demonstrated group meningitis with dexamethasone treatment $(0.2 \mathrm{mg} / \mathrm{kg} / 7$ days $)$. Data was presented as media and interquartile ranges, $n=10$ rats per group. ${ }^{*} P<0.05$ versus training.

formed (equivalent to the amount of sulphydryl $(\mathrm{SH})$ groups) were calculated. All the results were normalized by protein concentration measured by the Lowry assay [26].

2.3.4. Mitochondrial Superoxide. As an index of electron transporter chain (ETC) uncoupling, the generation of mitochondrial superoxide $\left(\mathrm{O}_{2}{ }^{-}\right)$was determined as previously described [28]. Superoxide dismutase (E.C. 1.15.1.1.) was used at $0.1-0.3 \mathrm{lM}$ final concentration as a negative control to confirm assay specificity.

2.3.5. Statistical Analysis. Data from the inhibitory avoidance task are reported as median and interquartile ranges and comparisons among groups were performed using MannWhitney $U$ tests. The within individual groups were analyzed by Wilcoxon tests. Data from the biochemical analyses were analyzed by one-way analysis of variance (ANOVA) followed by the Tukey test when $\mathrm{F}$ was significant and are expressed as mean \pm standard deviation. All analyses were performed using the Statistical Package for the Social Science (version 17.0) software.

\section{Results}

In Figure 1, we showed results from the step-down inhibitory avoidance test 10 days after pneumococcal meningitis induction. In the acute protocol there were not differences between groups in the training session performance $(P>$ 0.05). In the test session, there were not difference between training and test in the step-down latencies in the meningitis group $(P=0.153)$. However, the meningitis group with dexamethasone treatment $0.7 \mathrm{mg} / \mathrm{kg} / 1$ day showed statistical

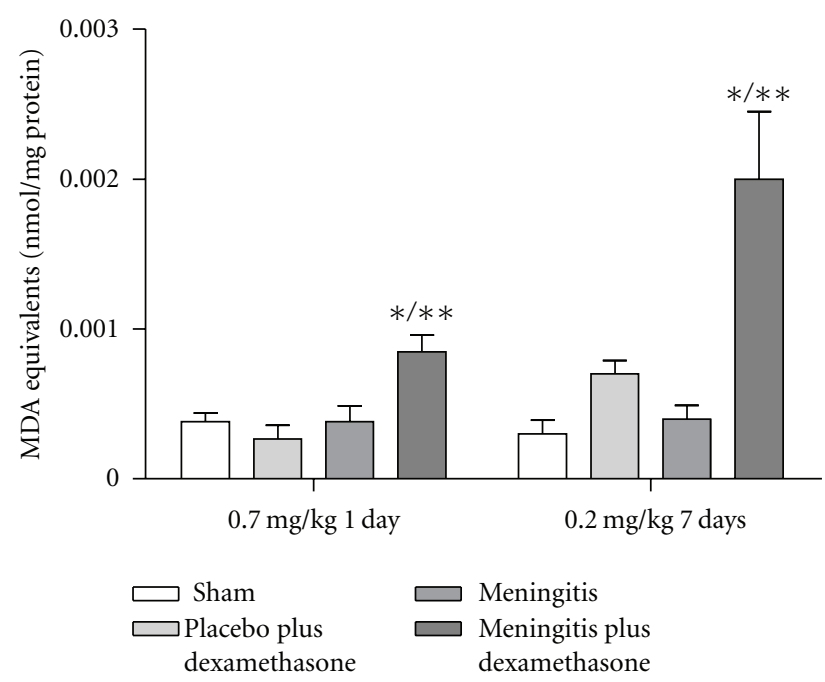

(a)

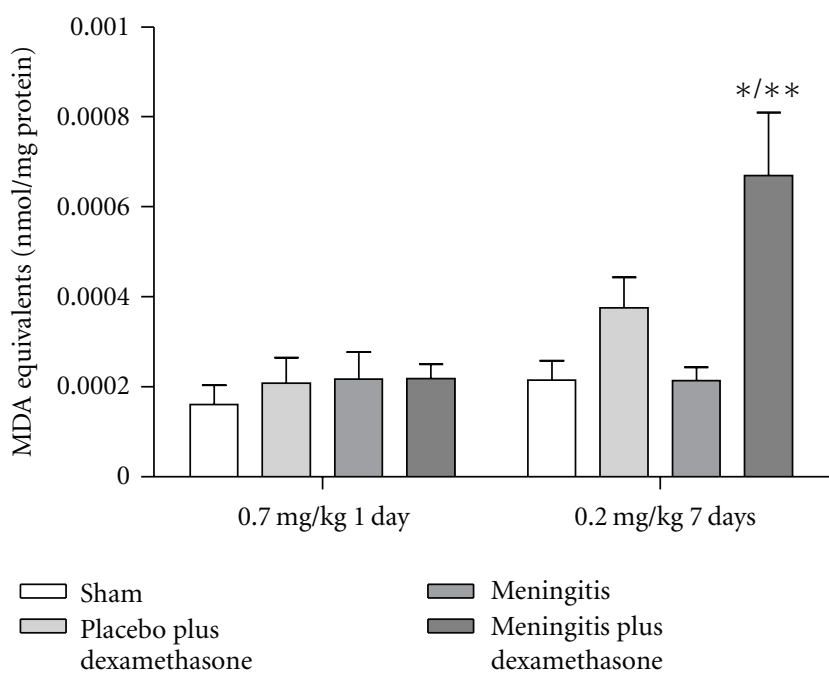

(b)

FIgure 2: Oxidative variables. TBARS. The thiobarbituric acid reactive species (TBARS) was evaluated in the hippocampus (a) and cortex (b), during the treatment with dexamethasone $(0.7 \mathrm{mg} / \mathrm{kg} / 1$ day or $0.2 \mathrm{mg} / \mathrm{kg} / 7$ days $)$. Values are expressed as mean $\pm \mathrm{SD}(n=5$ for each group). ${ }^{*}$ Different from sham $(P<0.05),{ }^{* *}$ different from sham with dexamethasone.

difference between training and test sessions $(P \leq 0.05)$. In the repeated dexamethasone protocol, there were not differences between groups in the training session $(P>0.05)$. In the test session, there were not difference in the step-down latency in the meningitis group $(P=0.080)$ and meningitis group treated with dexamethasone $0.2 \mathrm{mg} / \mathrm{kg} / 7$ days $(P=$ 0.240 ) when compared to the training session. The oxidative damage in lipids, TBARS, in hippocampus, Figure 2(a), was increased in meningitis groups with dexamethasone $(0.7 \mathrm{mg} / \mathrm{kg} / 1$ day and $0.2 \mathrm{mg} / \mathrm{kg} / 7$ days) when compared with the sham group $(P \leq 0.05)$ and Figure $2(\mathrm{~b})$, in cortex, was increased in meningitis group with dexamethasone treatment $(0.2 \mathrm{mg} / \mathrm{kg} / 7$ days $)$ when compared with the sham 


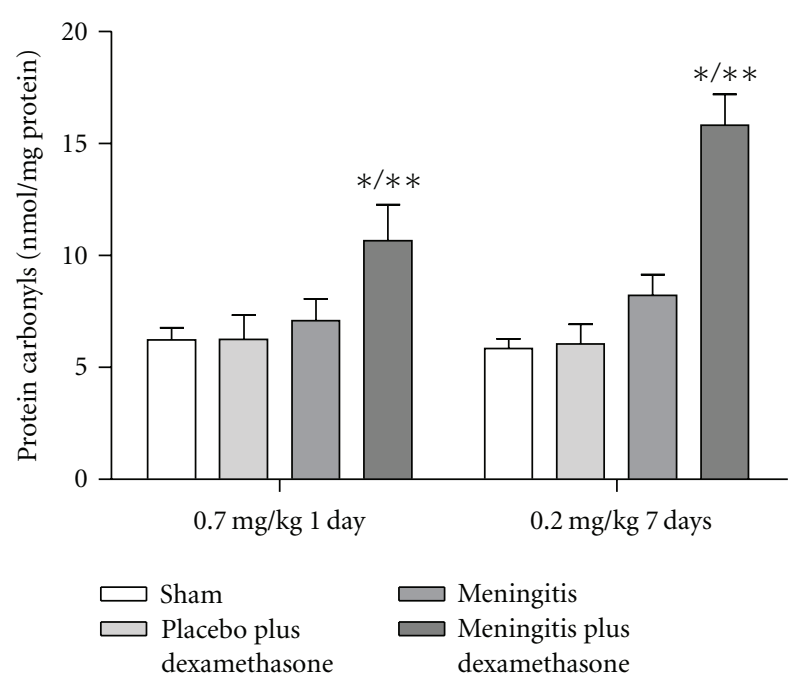

(a)

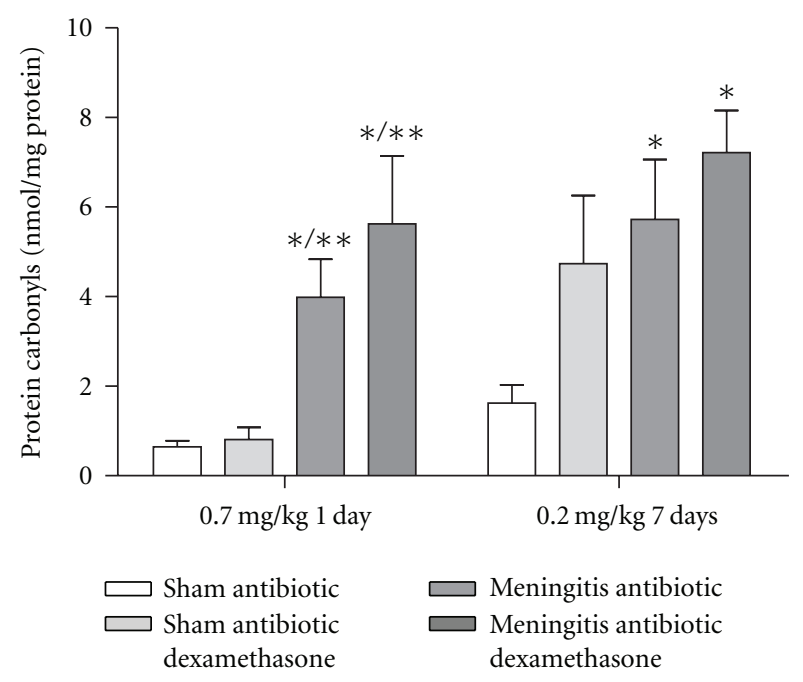

(b)

FIGURE 3: Protein carbonyl. The protein carbonyls was evaluated in the hippocampus (a), and cortex (b), during the treatment with dexamethasone $(0.7 \mathrm{mg} / \mathrm{kg} / 1$ day or $0.2 \mathrm{mg} / \mathrm{kg} / 7$ days $)$. Values are expressed as mean $\pm \mathrm{SD}$ ( $n=5$ for each group). ${ }^{*}$ Different from sham $(P<0.05), * *$ different from sham with dexamethasone.

$(P \leq 0.05)$. In Figure 3(a), in hippocampus, protein carbonyl assays, was increased in meningitis group with adjuvant dexamethasone treatment, respectively $(0.7 \mathrm{mg} / \mathrm{kg} / 1$ day and $0.2 \mathrm{mg} / \mathrm{kg} / 7$ days) when compared with the sham group $(P \leq 0.05)$. In Figure 3(b), in cortex, carbonyl levels were increased in meningitis group and meningitis group with dexamethasone treatments, respectively, with $(0.7 \mathrm{mg} / \mathrm{kg} / 1$ day and $0.2 \mathrm{mg} / \mathrm{kg} /$ days) when compared with the sham group $(P \leq 0.05)$. The integrity of proteins was measured by sulfhydryl ( $\mathrm{SH}$ ) groups in Figure 4(a); in the hippocampus, there was a decrease in the integrity of proteins in all groups with adjuvant treatment with dexamethasone and meningitis group. In cortex, all the groups with dexamethasone treatment $(0.7 \mathrm{mg} / \mathrm{kg} / 1$ day $)$ were decreased in the protein

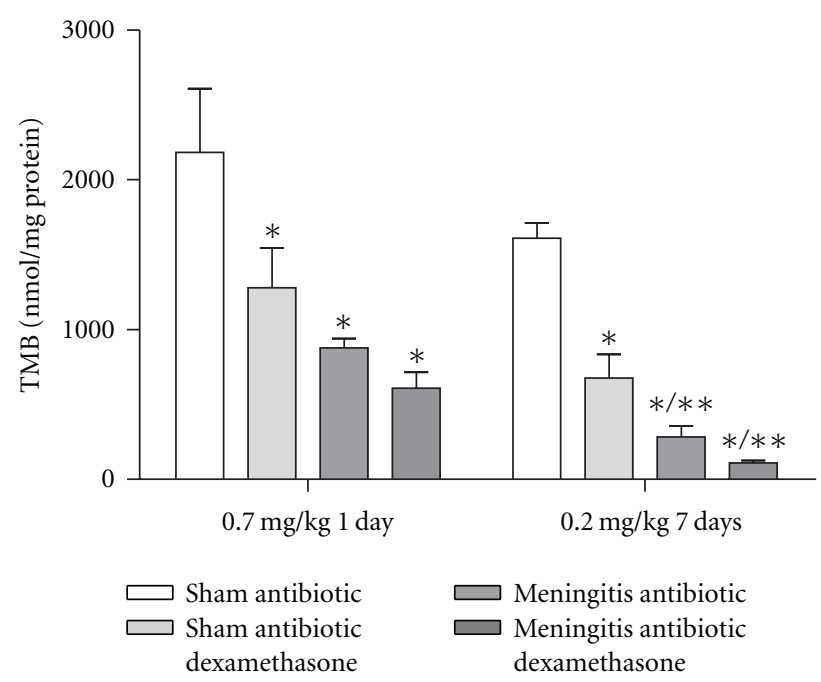

(a)

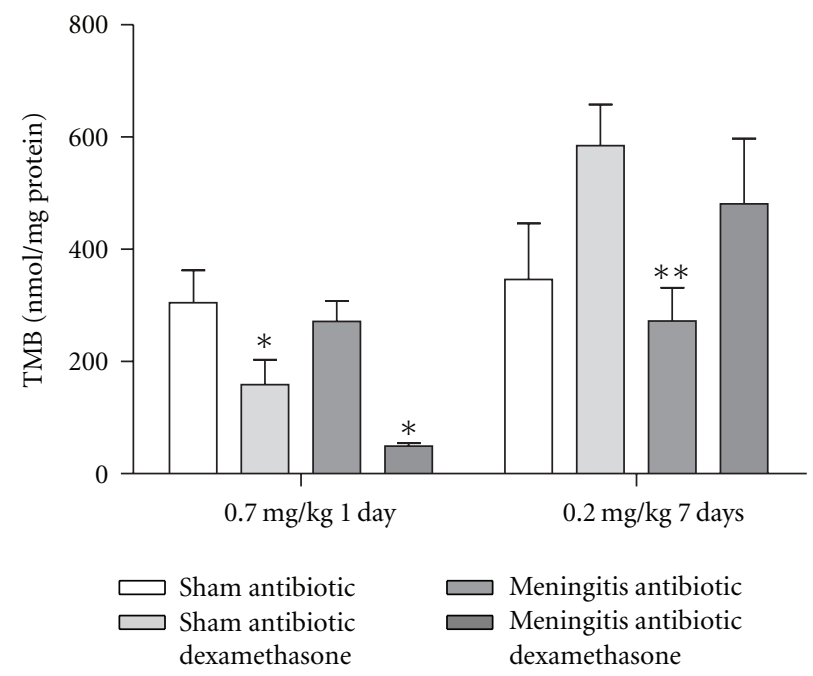

(b)

FIGURE 4: Sulphydryl groups. The sulphydryl groups was evaluated in the hippocampus (a) and cortex (b), during the treatment with dexamethasone $(0.7 \mathrm{mg} / \mathrm{kg} / 1$ day or $0.2 \mathrm{mg} / \mathrm{kg} / 7$ days $)$. Values are expressed as mean \pm SD $\left(n=5\right.$ for each group). ${ }^{*}$ Different from sham $(P<0.05),{ }^{* *}$ different from sham with dexamethasone.

integrity Figure 4(b) $(P \leq 0.05)$. We demonstrated in Figure 5(a), in hippocampus, and Figure 5(b), in cortex, that the increased activity of mitochondrial superoxide in the meningitis group with dexamethasone treatment $(0.2 \mathrm{mg} / \mathrm{kg} / 7$ days $)$, when compared with sham group $(P \leq$ $0.05)$.

\section{Discussion}

With S. pneumoniae proliferation in the subarachnoid space large amounts of subcapsular bacterial components are released, which includes lipopolysaccharide, lipoteichoic acid, pneumolysin, and bacterial DNA [29]. Bacterial components are recognized by Toll-like receptors (TLRs) or other 


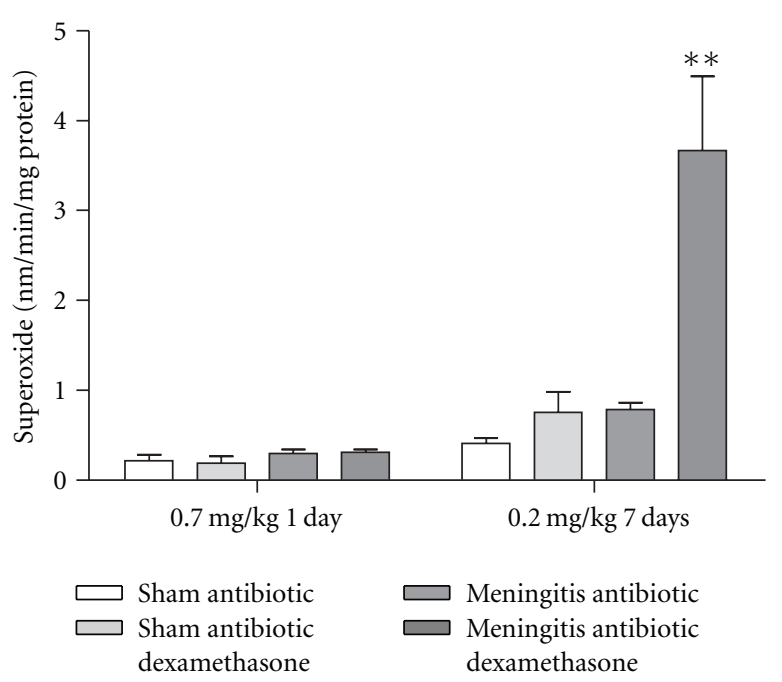

(a)

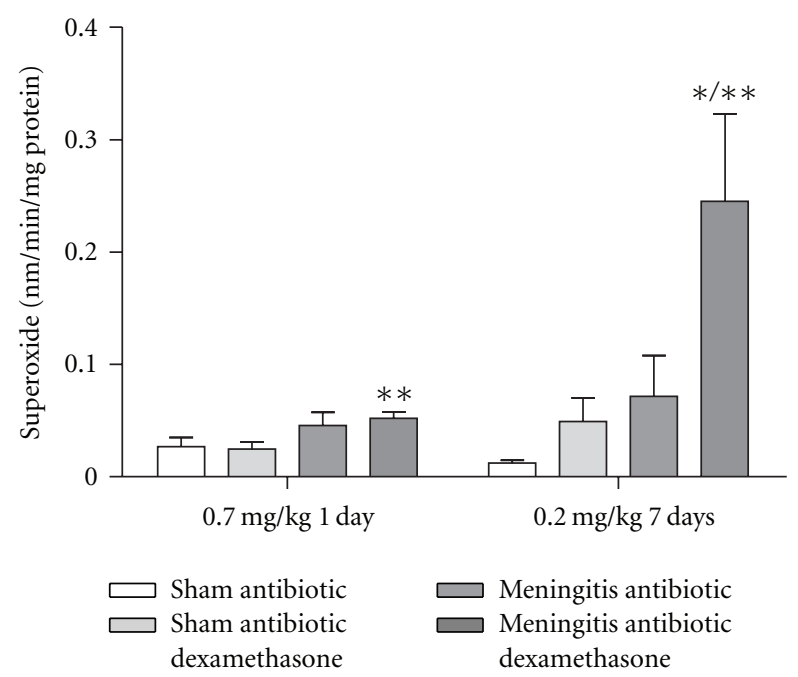

(b)

FIGURE 5: Mitochondrial superoxide dismutase (SOD). The SOD activity was evaluated in the hippocampus (a) and cortex (b) during the treatment with dexamethasone $(0.7 \mathrm{mg} / \mathrm{kg} / 1$ day or $0.2 \mathrm{mg} / \mathrm{kg} / 7$ days). Values are expressed as mean $\pm \mathrm{SD}$ ( $n=5$ for each group). *Different from sham $(P<0.05)$, ** different from sham with dexamethasone.

pathogen recognition receptors that lead to the activation of NF-kappaB, and it triggers the inflammatory cytokines expression. In consequence, polymorphonuclear leukocytes are attracted and activated; furthermore, the induction of nitric oxide synthase (iNOS) is expressed, producing large amounts of superoxide anion $\left(\mathrm{O}_{2}^{-}\right)$and nitric oxide (NO), leading to the peroxynitrite formation $\left(\mathrm{ONOO}^{-}\right)$. As a result, oxidative stress leads to cytokines and chemokines activation, enhancement of neutrophil activation, lipid peroxidation, DNA single-strand breaks, and mitochondrial damage [30]. Various pathophysiological alterations are induced, such as increased blood brain barrier permeability, brain edema, intracranial hypertension, and thrombosis, which may cause learning deficits, neuropsychiatric impairment, sensory motor deficits, blindness, and deafness [31].
Glucocorticoids are used in clinical conditions, where their immunosuppressive properties are supposed to account for their beneficial effects [4]. Adjunctive treatment with dexamethasone is associated with an inflammatory process reduction in the subarachnoid space [32]; it decreased the caspase- 3 activation, inhibited the MMP-9 expression in the rat brains inoculated with S. pneumoniae [12], and improved neurologic outcomes in meningitis $[13,14]$. We verified that treatment with dexamethasone administered in a single dose prior the antibiotic therapy prevented the cognitive impairment in animals induced with pneumococcal meningitis. At the same time, this adjuvant treatment induced the lipid peroxidation and protein carbonyls, decreased cellular integrity in hippocampus and increased mitochondrial superoxide activity levels. It has been expressed that steroids reduce the blood-brain permeability and thereby the antibiotics penetration into the subarachnoid space [33]. Irazuzta et al., 2005 , verified the performance in the water maze task was improved in animals treated with dexamethasone, suggesting that dexamethasone attenuates meningitis memory deficits [13]. Bacteriolytic antibiotics cause the release of bacterial components that augment the host inflammatory response, which, in turn, contributes to the brain injury in bacterial meningitis [21]. This highly proinflammatory response would be inhibited with the use of dexamethasone treatment before the first antibiotic dose. Leib and coworkers [15] showed a significantly impaired learning performance in infected infant rats by pneumococcal meningitis treated with dexamethasone $(0.7 \mathrm{mg} / \mathrm{kg}$ with an interval of 8 hours from 18 to $34 \mathrm{~h}$ ) when compared with the control group. We also verified, in our results, that the prolonged dexamethasone use did not prevent cognitive impairment in animal model. In four trials including children with Haemophilus influenzae meningitis, dexamethasone reduced the frequency of neurological sequels and sensorineural hearing loss $[34,35]$. Likewise, in the European study, it was showed that adjunctive therapy with dexamethasone reduced the unfavorable outcomes rate from 25 to $15 \%$ in adults with bacterial meningitis; adjunctive treatment with dexamethasone was given before or with the first antibiotics dose [36]. Dexamethasone inhibits the production of TNF$\alpha$ and IL- $1 \beta$, reduces brain edema, and limits the increase in cerebrospinal fluid lactate and leukocyte concentrations [4]. van de Beek and colleagues, 2010 [37], published the meta-analysis of 2029 patients from five trials. They verified that adjunctive dexamethasone treatment in acute bacterial meningitis therapy did not seem to significantly reduce death or neurological disability. There were no significant treatment effects in any of the prespecified subgroups. The benefit of adjunctive dexamethasone treatment for all or any subgroup of patients with bacterial meningitis thus remained unproven. We verified that treatment with dexamethasone, with one dose, before the beginning of antibiotic therapy reduces cognitive damage in animals induced with pneumococcal meningitis.

\section{Conflict of Interests}

The authors have no conflict of interests. 


\section{Acknowledgment}

This research was supported by grants from CNPq, FAPESC, UNESC, and Instituto Nacional de Ciência e Tecnologia Translacional em Medicina (INCT-TM).

\section{References}

[1] C. T. Brandt, "Experimental studies of pneumococcal meningitis," Danish Medical Bulletin, vol. 57, no. 1, p. B4119, 2010.

[2] D. van de Beek, D. B. Schmand, J. de Gans et al., "Cognitive impairment in adults with good recovery after bacterial meningitis," Journal of Infectious Diseases, vol. 186, no. 7, pp. 1047-1052, 2002.

[3] R. Nau, A. Soto, and W. Brück, "Apoptosis of neurons in the dentate gyrus in humans suffering from bacterial meningitis," Journal of Neuropathology and Experimental Neurology, vol. 58, no. 3, pp. 265-274, 1999.

[4] D. van de Beek, "Corticosteroids for acute adult bacterial meningitis," Medecine et Maladies Infectieuses, vol. 39, no. 7-8, pp. 531-538, 2009.

[5] L. S. Leib and G. M. Tauber, "Pathogenisis of bacterial meningitis," Infectious Disease Clinics of North America, vol. 13, no. 3, pp. 527-548, 1999.

[6] B. R. Nathan and M. W. Scheld, "New advances in the pathogenesis and pathophysiology of bacterial meningitis," Current Infectious Disease Reports, vol. 2, no. 4, pp. 332-336, 2000.

[7] G. Cohen, "Oxygen radicals and Parkinson's disease," in Oxygen Radical and Tissue Injury, B. Halliwell, Ed., pp. 130-135, Federation of American Societies for Experimental Biology, Bethesda, Md, USA, 1988.

[8] R. A. Floyd, "Antioxidants, oxidative stress, and degenerative neurological disorders," Proceedings of the Society for Experimental Biology and Medicine, vol. 222, no. 3, pp. 236-245, 1999.

[9] S. Christen, M. Schaper, J. Lykkesfeldt et al., "Oxidative stress in brain during experimental bacterial meningitis: differential effects of $\alpha$-phenyl-tert-butyl nitrone and $\mathrm{N}$-acetylcysteine treatment," Free Radical Biology and Medicine, vol. 31, no. 6, pp. 754-762, 2001.

[10] S. Kastenbauer and H. W. Pfister, "Protection against meningitis-associated central nervous system complications by uric acid," Medical Hypotheses, vol. 58, no. 5, p. 431, 2002.

[11] F. A. Rucián, G. G. D. Cerro, F. C. Usandizaga, M. T. Rué, X. Martínez Gómez, and F. A. Moraga-Llop, "Treatment of pneumococcal meningitis with dexamethasone," Anales de Pediatria, vol. 74, no. 1, pp. 38-41, 2011.

[12] X. Liu, Q. Han, R. Sun, and Z. Li, "Dexamethasone regulation of matrix metalloproteinase expression in experimental pneumococcal meningitis," Brain Research, vol. 1207, pp. 237-243, 2008.

[13] J. Irazuzta, R. K. Pretzlaff, G. de Courten-Myers, F. Zemlan, and B. Zingarelli, "Dexamethasone decreases neurological sequelae and caspase activity," Intensive Care Medicine, vol. 31, no. 1, pp. 146-150, 2005.

[14] J. Irazuzta, K. Robert, and K. R. Pretzlaff, "Caspases inhibition decreases neurological sequelae in meningitis," Critical Care Medicine, vol. 36, no. 5, pp. 1603-1606, 2008.

[15] S. L. Leib, C. Heimgartner, Y. D. Bifrare, J. M. Loeffler, and M. G. Täuber, "Dexamethasone aggravates hippocampal apoptosis and learning deficiency in pneumococcal meningitis in infant rats," Pediatric Research, vol. 54, no. 3, pp. 353-357, 2003.
[16] R. S. Coimbra, G. Loquet, and S. L. Leib, "Limited efficacy of adjuvant therapy with dexamethasone in preventing hearing loss due to experimental pneumococcal meningitis in the infant rat," Pediatric Research, vol. 62, no. 3, pp. 291-294, 2007.

[17] J. E. Irazuzta, R. K. Pretzlaff, B. Zingarelli, V. Xue, and F. Zemlan, "Modulation of nuclear factor- $\kappa \mathrm{B}$ activation and decreased markers of neurological injury associated with hypothermic therapy in experimental bacterial meningitis," Critical Care Medicine, vol. 30, no. 11, pp. 2553-2559, 2002.

[18] D. Grandgirard, O. Steiner, M. G. Täuber, and S. L. Leib, "An infant mouse model of brain damage in pneumococcal meningitis," Acta Neuropathologica, vol. 114, no. 6, pp. 609$617,2007$.

[19] J. E. Irazuzta, G. de Courten-Myers, F. P. Zemlan, M. Y. V. Bekkedal, and J. Rossi, "Serum cleaved Tau protein and neurobehavioral battery of tests as markers of brain injury in experimental bacterial meningitis," Brain Research, vol. 913, no. 1, pp. 95-105, 2001.

[20] T. Barichello, I. dos Santos, G. D. Savi et al., "Tumor necrosis factor $\alpha$ (TNF- $\alpha$ ) levels in the brain and cerebrospinal fluid after meningitis induced by Streptococcus pneumoniae," Neuroscience Letters, vol. 467, no. 3, pp. 217-219, 2009.

[21] D. Grandgirard, C. Schürch, P. Cottagnoud, and S. L. Leib, "Prevention of brain injury by the nonbacteriolytic antibiotic daptomycin in experimental pneumococcal meningitis," Antimicrobial Agents and Chemotherapy, vol. 51, no. 6, pp. 2173-2178, 2007.

[22] O. J. Cassol-Jr, C. M. Comim, F. Petronilho et al., "Low dose dexamethasone reverses depressive-like parameters and memory impairment in rats submitted to sepsis," Neuroscience Letters, vol. 473, no. 2, pp. 126-130, 2010.

[23] T. Barichello, G. Z. Silva, J. S. Generoso et al., "Time-dependent behavioral recovery after pneumococcal meningitis in rats," Journal of Neural Transmission, vol. 117, no. 7, pp. 819826, 2010.

[24] H. Esterbauer and K. H. Cheeseman, "Determination of aldehydic lipid peroxidation products: malonaldehyde and 4hydroxynonenal," Methods in Enzymology, vol. 186, pp. 407421, 1990.

[25] R. L. Levine, J. A. Williams, E. R. Stadtman, and E. Shacter, "Carbonyl assays for determination of oxidatively modified proteins," Methods in Enzymology, vol. 233, pp. 346-357, 1994.

[26] O. H. Lowry, N. J. Rosebrough, A. L. Farr, and R. J. Randall, "Protein measurement with the Folin phenol reagent," The Journal of Biological Chemistry, vol. 193, no. 1, pp. 265-275, 1951.

[27] P. W. Riddles, R. L. Blakeley, and B. Zerner, "Reassessment of Ellman's reagent," Methods in Enzymology, vol. 91, pp. 49-60, 1983.

[28] J. J. Poderoso, M. C. Carreras, C. Lisdero, N. Riobó, F. Schöpfer, and A. Boveris, "Nitric oxide inhibits electron transfer and increases superoxide radical production in rat heart mitochondria and submitochondrial particles," Archives of Biochemistry and Biophysics, vol. 328, no. 1, pp. 85-92, 1996.

[29] R. A. Hirst, A. Kadioglu, C. O'Callaghan, and P. W. Andrew, "The role of pneumolysin in pneumococcal pneumonia and meningitis," Clinical and Experimental Immunology, vol. 138, no. 2, pp. 195-201, 2004.

[30] M. Klein, U. Koedel, and H. W. Pfister, "Oxidative stress in pneumococcal meningitis: a future target for adjunctive therapy?” Progress in Neurobiology, vol. 80, no. 6, pp. 269-280, 2006. 
[31] J. Sellner, M. G. Täuber, and S. L. Leib, "Pathogenesis and pathophysiology of bacterial CNS infections," Handbook of Clinical Neurology, vol. 96, pp. 1-16, 2010.

[32] M. G. Tauber, H. Khayam-Bashi, and M. A. Sande, "Effects of ampicillin and corticosteroids on brain water content, cerebrospinal fluid pressure, and cerebrospinal fluid lactate levels in experimental pneumococcal meningitis," Journal of Infectious Diseases, vol. 151, no. 3, pp. 528-534, 1985.

[33] D. van de Beek, J. de Gans, P. McIntyre, and K. Prasad, "Steroids in adults with acute bacterial meningitis: a systematic review," Lancet Infectious Diseases, vol. 4, no. 3, pp. 139$143,2004$.

[34] C. M. Odio, I. Faingezicht, M. Paris et al., "The beneficial effects of early dexamethasone administration in infants and children with bacterial meningitis," New England Journal of Medicine, vol. 324, no. 22, pp. 1525-1531, 1991.

[35] D. van de Beek, J. de Gans, P. McIntyre, and K. Prasad, "Corticosteroids for acute bacterial meningitis," Cochrane Database of Systematic Reviews, vol. 24, no. 1, p. 4405, 2007.

[36] J. de Gans and D. van de Beek, "European: dexamethasone in adulthood bacterial meningitis study investigators. Dexamethasone in adults with bacterial meningitis," The New England Journal of Medicine, vol. 347, no. 20, pp. 1549-1556, 2002.

[37] D. van de Beek, J. J. Farrar, J. de Gans et al., "Adjunctive dexamethasone in bacterial meningitis: a meta-analysis of individual patient data," The Lancet Neurology, vol. 9, no. 3, pp. 254-263, 2010 . 


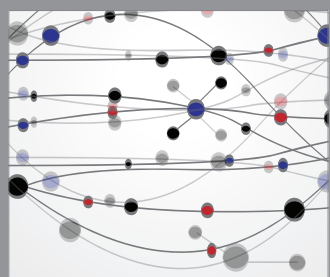

The Scientific World Journal
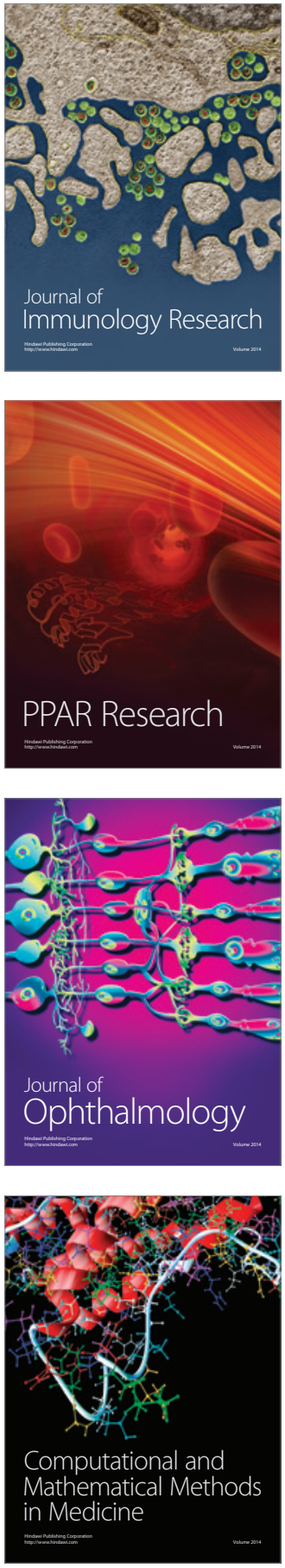

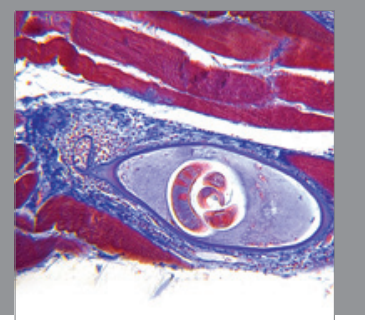

Gastroenterology

Research and Practice
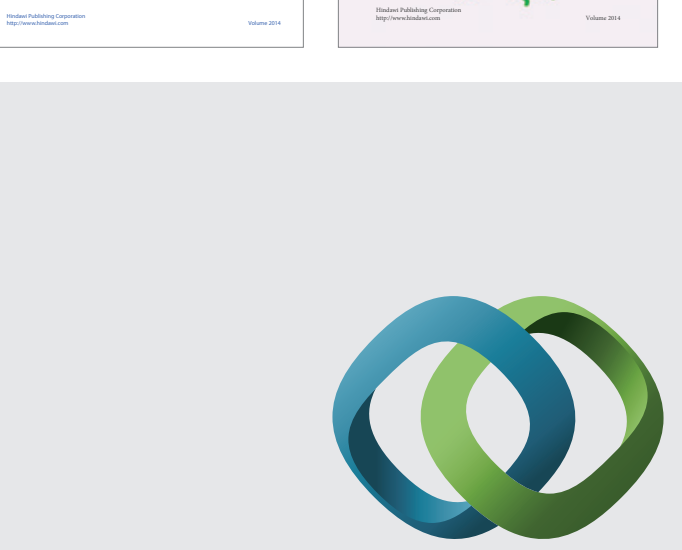

\section{Hindawi}

Submit your manuscripts at

http://www.hindawi.com
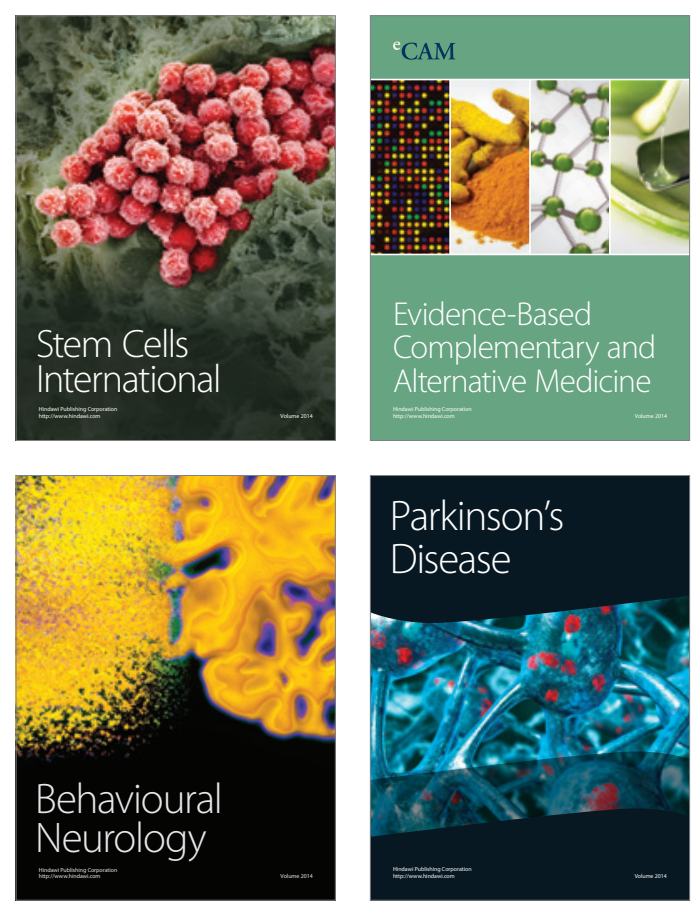

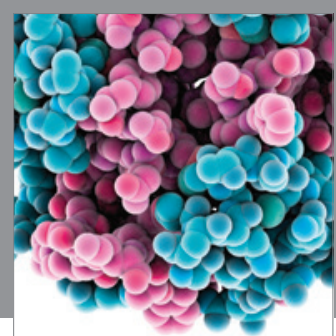

Journal of
Diabetes Research

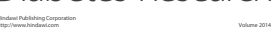

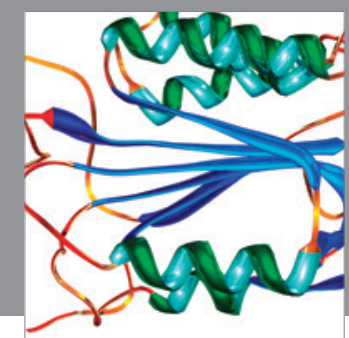

Disease Markers
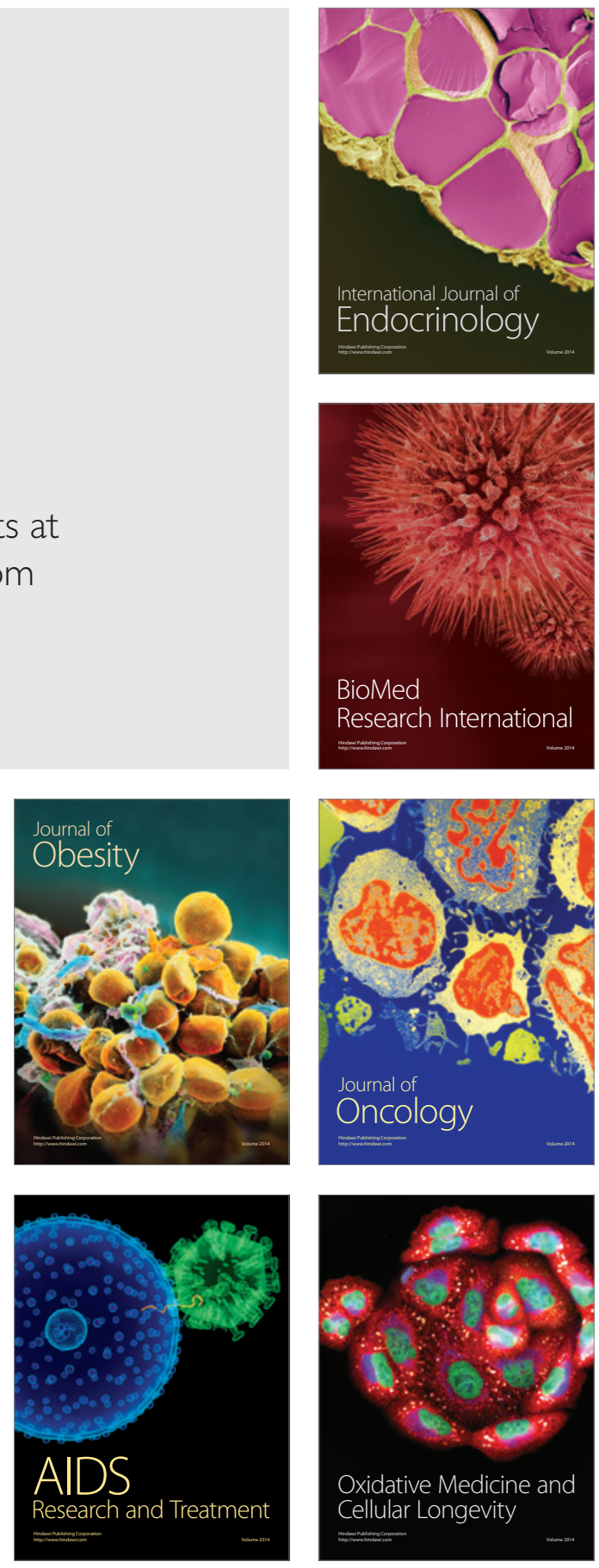